\title{
The Life Cycle of a Facebook Post
}

\author{
Martin S. Fiebert*, Azadeh Aliee, Hoda Yassami and Marcie D. Dorethy
}

California State University, Long Beach, USA

\begin{abstract}
Social networking sites, such as Facebook, offer a fast-paced medium for social interaction. Consequently the amount of social engagement that users produce tends to be short-lived. The current study investigates the length of time a Facebook post continues to engage users. The posts of 100 participants, 50 men and 50 women, were followed for a $24-$ hour period. Results indicate that on average they receive the largest number of social engagements (i.e., likes and comments) within the first 2 to 4 hours (53\%), and rarely after 24 hours.
\end{abstract}

Keywords: Facebook, social networking.

In 2013, Facebook reported over 1 billion active monthly users [1] and, to date, it remains the most popular social networking site [2]. Approximately $71 \%$ of Internet users [3] are on Facebook. Therefore, it is an abundant source of information on social connectedness [4]. Researchers can study individuals in varying demographic groups and geographic locales and in a naturalistic setting [4].

Various social motivations [5] seem to determine the online behavior by Facebook users. Most utilize it to enhance existing real-world relationships [5], and share content as a means of "keeping in touch" with others [6]. Previous study shows that online personas appear to reflect offline personalities fairly closely [7], although to some extent they are slightly idealized [8].

Sharing information about one's life has become a hallmark of online social connectedness. Users reported that is the way they keep in touch with family and friends but that they spend the majority of their time observing the content posted by others [9] rather than posting content themselves. Furthermore, their response marked by liking or commenting appears to account for only a small percentage of the overall time spent online. For example, one study reported that Facebook users like content an average of 14 times per month [2], a relatively small number when compared with another study that shows $64 \%$ of users visiting the site at least once per day [6]; therefore, the little social engagement relative to the length of time spent on the site appears to demonstrate its fast-paced, consumer-driven nature. There is only a short period of time in which the user engages with the content before the next story takes over. Examining the time span of a Facebook post can help us better understand the nature of the site, and warrants further study.

Over the past two years, the Facbook research group at California State University, Long Beach has investigated the

*Address correspondence to this author at the Department of Psychology, California State University, Long Beach, USA; Tel: 562-985-5027;

Fax: 562-985-8004; E-mail: Martin.Fiebert@csulb.edu site's various social phenomena: birthday greetings as a function of gender and relationship status [10]; five unique Facebook typologies [11]; their relative stability [12]; photo sharing as a means of online impression management [13]; and SNS behaviors according to age cohort [14]. The present study extends this research and by examining what we call the life cycle of a single Facebook post. We postulated that like organic life forms a virtual life form like a Facebook post would exist for a specific period of time, less than that of a desert tortoise and more like that of a mayfly - that is, twenty-four hours. Furthermore, we hypothesized that a post would be born and then nurtured through likes and comments for only a few hours, in fact, that it would receive the majority of social engagement within the first 2 to 6 hours and cease interaction after 24 hours.

\section{METHODS}

\section{Participants}

A convenient sample of 100 participants, 50 men and 50 women, $M_{\text {age }}=23.34$, age range: $18-28$ years, was selected from among Facebook users based primarily on their accessibility. Selection was random, but individuals who posted infrequently (e.g., less than 2 times per week) were excluded.

\section{Procedure}

Prior to data collection, research assistants (RAs) were recruited from an introductory psychology course at California State University, Long Beach. In return for course credit, each one agreed to monitor a Facebook post. They were instructed to select the most recent post from their news feed. They recorded the participants' age and gender and followed the post for the next 24 hours. The number of comments and likes was recorded at two-hour intervals. After the first twenty-four hours they were to revisit the post for another twenty-four hours to determine whether additional social engagement had occurred. 


\section{RESULTS}

For the purpose of analysis, social engagement was defined as the number of likes and comments received within a given time period; accordingly, social engagement measures reported represent an aggregate of both constructs. On average, social engagement peaked about 7 hours after initial posting $(M=6.73, S D=5.82)$. Surprisingly, posts shared by female users appear to have a longer life span $(M=8.66, S D=6.72)$ than those posted by males $(M=4.80$, $S D=3.96$. More than one-third (38\%) of the posts analyzed received peak social engagement within the first two hours of being posted. At four hours, only $15 \%$ of posts received peak social engagement, followed incrementally by $9 \%$ at 6 hours, $10 \%$ at 8 hours, $8 \%$ at 10 hours, and $9 \%$ at 12 hours. From 12 to 24 hours, only one or two posts per increment received peak engagement. Additionally, within the 100 statuses observed, only one post received additional social engagement after the twenty-four hour period.

\section{DISCUSSION}

The results of the study support our hypotheses. Like the mayfly Facebook posts appear to have a very short life span. Our analysis shows that social engagement peaks within the first 2 to 4 hours and disappears almost completely after 24 hours. We attribute this brevity to the fast-pace of social networking sites along with the enormous competition among the several sites and among postings. The current study provides a time line of a Facebook post, and brings us a step closer to a broader understanding of online social engagement.

The significant difference between male and female posts' existence suggests the need for further to determine whether this finding is a function of factors such as the number of Facebook friends, the nature of the relationships, gender, and age.

We hope that future research will capture a more varied demographic, measure shorter intervals, and examine content to see its effects on time span. A previous study showed that social engagement generated by picture sharing varied by the tone and content of the photo presented [13]. Similarly, posts might provoke lengthier response because of their specific content such as a photo rather than a text.

\section{CONFLICT OF INTEREST}

The authors confirm that this article content has no conflict of interest.

\section{ACKNOWLEDGEMENTS}

Declared none.

\section{REFERENCES}

[1] Facebook. Key facts. [Retrieved: $6^{\text {th }}$ February, 2014], Available from: http://newsroom.fb.com/Key-Facts

[2] Duggan M, Smith A. Social media update 2013. Retrieved from http://www.pewinternet.org/2013/12/30/social-media-update-2013/

[3] Pew Research Social Networking Fact Sheet. $\left(27^{\text {th }}\right.$ December, 2013). Retrieved from http://www.pewinternet.org/factsheets/social-networking-fact-sheet/

[4] Wilson RE, Gosling SD, Graham LT. A review of Facebook research in the social sciences. Perspect Psychol Sci 2012; 7(3): 203-20. doi:10.1177/1745691612442904

[5] Carpenter JM, Green MC, LaFlam J. People or profiles: Individual differences in online social networking use. Pers Indiv Differ 2011; 50(5): 538-41. doi:10.1016/j.paid.2010.11.006

[6] Pempek TA, Yermolayeva YA, Calvert SL. College students' social networking experiences on Facebook. J Appl Dev Psychol 2009; 30(3): 227-38. doi:10.1016/j.appdev.2008.12.010

[7] Back MD, Stopfer JM, Vazire S, et al. Facebook profiles reflect actual personality, not self-idealization. Psychol Sci 2010; 21(3): 372-4. doi:10.1177/0956797609360756

[8] Zhao S, Grasmuck S, Martin J. Identity construction on Facebook: Digital empowerment in anchored relationships. Comput Hum Behav 2008; 24(5): 1816-36. doi:10.1016/j.chb.2008.02.012

[9] Greenwood DN. Fame, facebook, and twitter: how attitudes about fame predict frequency and nature of social media use. Psychol Pop Media Cult 2013; 2(4): 222-36.

[10] Fiebert MS, Tilmont L, Warren CR. It's your birthday!: Greetings as a function of gender and relationship status on facebook. Int Rev Soc Sci Humanit 2013; 4(2): 206-8.

[11] Fiebert MS. The origins and development of a typology of Facebook users. Int Rev Soc Sci Humanit 2013; 5(2): 115-6.

[12] Stal M, Fiebert MS. Changes in Facebook behavior over time. Glob J Comput Sci Technol 2014; 13(2): 1-4.

[13] Dorethy MD, Fiebert MS, Warren CR. Examining social networking site behaviors: photo sharing and impression management on Facebook. Int Rev Soc Sci Humanit 2013; 6(2): 111-6.

[14] Luevano L, Fiebert MS, Warren CR. Examining the differences in online social network activity among different age cohorts. J Scholast Inquiry: Behav Sci (in press).

Received: February 16, 2014

Revised: May 21, 2014

Accepted: May 21, 2014

(C) Fiebert et al.; Licensee Bentham Open.

This is an open access article licensed under the terms of the Creative Commons Attribution Non-Commercial License (http://creativecommons.org/licenses/ by-nc/3.0/) which permits unrestricted, non-commercial use, distribution and reproduction in any medium, provided the work is properly cited. 